\title{
Von der Gabe, das Zeitliche zu segnen
}

EinVers aus dem Hiobbuch (Hi 1,21) wird häufig in der Grabliturgie zitiert: »Ich bin nackt von meiner Mutter Leibe gekommen, nackt werde ich wieder dahinfahren. Der Herr hat's gegeben, der Herr hat's genommen; der Name des Herrn sei gelobt! « Am Grab, angesichts der offensichtlichen Lebensendes eines Menschen, wird uns das Elementare dieser Aussage bewusst. Wir realisieren, dass unser Leib und Leben Gaben auf Zeit sind und dass wir das Zeitliche segnen müssen und dennoch den Ewigen loben dürfen.

Am Ende wird diese Zumutung der menschlichen Existenz schärfer erkennbar. Leben ist eine Gabe auf Zeit. Diese Sicht hat zunächst etwas Bedrohliches. Menschliches Leben steht unter dem Bann eines Zeitlimits. Vom Ende her gesehen wird die göttliche Gnade, die Lebenszeit gewährt, zur Gnadenfrist. Die religiöse Rede schafft mit der Figur des Ewigen alternative Möglichkeiten, um das Bedrohliche dieser Sicht abzuwehren. Leben ist mehr als eine Galgenfrist. Wenn Leben in Fülle möglich ist, wird das Ende möglicherweise zum Übergang. Die Rede vom ewigen Leben soll also die vernichtende Botschaft des Todes vernichten. Sie bleibt aber als religiöse Möglichkeit, gerade weil sie offensichtlich existentiell notwendig und denkerisch nicht zwingend ist, zwiespältig. Wenn Ewigkeit zur Überwindung der Angst vor der Vernichtung aufgeboten wird, könnte sie sich ja als ein Produkt menschlicher Fantasie und Ausdruck der Todesangst eines Wesens erweisen, dass sich im Laufe der Evolution seiner limitierten Existenz bewusst wird.

Das Begehren, bei Gott zu sein und zu bleiben, ist aber für den, der Vertrauen in Gottes Güte hat, mehr als notwendig. Dass unsere leibliche Existenz eine Gabe auf Zeit ist, heisst nicht, dass es eine Beschränkung gibt, innerhalb derer wir dies oder das erfüllen müssten, um nach dem Tod ein neuen Dasein zu fristen. WerVertrauen in den Ewigen hat, erkennt in der Befristung des Lebens einen Gewinn. Menschen dürfen das Zeitliche segnen. Sie sind dazu begabt! Götter können sich das nicht leisten. Die Rede vom ewigen Leben hat von dieser Warte her betrachtet nicht den Charakter der immerwährenden Dauer. Die Prolongation des Zeitlichen bleibt im System des Zeitlichen und dem Zeitlichen verhaftet. Wenn aber die Ewigkeit, um nicht vom Zeitlichen verschlungen zu werden, nur mit dem Ewigen zusammen gedacht werden muss und, um ewig zu bleiben, 
nicht mit dem Zeitlichen zusammen fallen darf, ist eine Kategorie angedacht, die nicht zu unseren kategorialen Denkvoraussetzungen passt. In Raum und Zeit von der Ewigkeit zu reden, ist menschlich gesehen vermessen oder religiös betrachtet ein Versprechen.

Das Versprechen Gottes gegenüber seinen Geschöpfen hat eine Entsprechung im Menschen, der sich seinem Schöpfer verspricht. Paulus redet in Röm 12,1 von der Leibdimension, um die theonome Reziprozität des Gottesdienstes zu charakterisieren, wenn er mahnt: "Dass ihr eure Leiber hingebt als ein Opfer, das lebendig, heilig und Gott wohlgefällig ist. Das sei euer vernünftiger Gottesdienst«. Wenn Gottesdienst mit Paulus als eine Gabe der Lebenszeit verstanden wird, kann nichts in Raum und Zeit, weder ein Bezirk noch eine Phase, davon ausgenommen werden. Dann wird die Trennung von heilig und profan ebenso hinfällig, wie ein scharfe Unterscheidung von Zeit und Ewigkeit. Die Hingabe oder der Dienst für Gott, der sich in der Lebenszeit und im Lebensraum ausbreitet, erfüllt die Zeit mit der Gegenwart des Ewigen. So qualifiziert das Ewige die Zeit. Kommt diese qualifizierte Zeit ins Spiel, macht sie die Gabe als Gabe erkennbar, weckt Reue über Versäumtes, Freude an der Fülle und Dankbarkeit für Empfangenes.

Die Gottesdienstfeier ist eine durch Ewigkeit qualifizierte Zeit. Er dauert, Gott sei Dank, nicht ewig! Kein Mensch kann ohne Unterbruch ein Leben lang hingebungsvoll für die Gabe des Lebens danken. Das können sich nur Engel leisten. Wer das Zeitliche segnet und sein Dasein fristet, muss von Zeit zu Zeit etwas für seinen Lebensunterhalt tun. Dass aber von Zeit zu Zeit auch das Ewige ins Spiel gebracht wird, ist mehr als notwendig. Wenn wir das Gespür für diesen Kairos verlieren, droht uns die chronische Lebenssorge. Der allgemeine Gottesdienst »braucht» deshalb die Liturgie. Ihr kommt die Aufgabe zu, den Alltag zu unterbrechen und dem Leben Glanz $\mathrm{zu}$ verleihen. Die Feier ist eine Zeit, um das Zeitliche zu segnen, um Gott eine lebendige, heilige und wohlgefällige Gabe zu geben. Der Akt der Hingabe ist kein Rühmen eigener Leistungen, sondern ein Lob der Gnade. Im Akt dieser Gabe verdichtet sich das Bewusstsein für das, was wir empfangen haben. Die Gemeinde versammelt sich ja nicht, um zu schwatzen und zu plappern. (Das leistet allenfalls der Kirchenkaffee im Anschluss an die Feier). Sie hört zuerst auf das lebendige Wort, das die Liebe versorgt, den Glauben nährt und die Hoffnung weckt. Sie verharrt im Gebet, um Gott anzubeten und für Menschen in Not einzustehen.

Im Licht dieser Fülle wird freilich der Schatten jener Leere erkennbar, die uns lebenslänglich droht - hin und wieder auch in einem 
langweiligen Gottesdienst. Das sollten wir uns eigentlich nicht leisten! Zeit zu verplempern, zu rauben oder tot zu schlagen! Was heisst es dann, wenn jemand Zeit gibt? Es heisst, dass ein Mensch mit sich oder anderen etwas anzufangen weiss. Das ist etwas anderes, als anderen eine Frist - sei es eine Gnadenfrist oder eine Galgenfrist - zu gewähren. Wer Zeit gibt, setzt einen Anfang. Wer neue Möglichkeiten ins Spiel bringt, schafft Zeit. Wenn Kirchenverantwortliche das Lamento von gottesdienstscheuen Zeitgenossen anstimmen, beklagen sie den Umstand, dass sich nur noch ganz wenige Zeit für den Gottesdienst nehmen. Vielleicht haben aber diese Menschen bei ihrem letzten Kirchenbesuch zu wenig Zeit bekommen? Vielleicht mussten sie bei einem langweiligen Sermon die Zeit totschlagen?

Menschen erwarten zu Recht von einem (guten) Gottesdienst, dass er nicht langweilig ist, also Zeit gibt und nicht raubt, also einen Neuanfang schenkt. Umgekehrt kann, wer sich keine Zeit nimmt für den Gottesdienst, auch nicht mit Zeit begabt werden. Im gottesdienstlichen Akt wird das Versprechen des ewigen Lebens erfüllt. Wenn auch keine Drohung, so ist darin doch die Mahnung gegeben, hier und jetzt auf die Gnade zu hören. Das sollten sich alle Lebenden leisten! Die Mahnung ist keine Drohung, weil selbst dann, wenn einer das Zeitliche gesegnet hat, vom Neuanfang die Rede sein darf. Die österliche Botschaft bringt ja eine Möglichkeit ins Spiel, die neue Zeit schafft und schenkt.

Auch Jochen Klepper droht nicht, aber mahnt mit der Zuversicht des Betenden: »Da alles, was der Mensch beginnt, / vor seinen Augen noch zerrinnt, / sei Du selbst derVollender. / Die Jahre, die du uns geschenkt, / wenn dein Güte uns nicht lenkt, / veralten wie Gewänder.«Klepper verspricht im Schlussvers seines Neujahrsliedes die Zuversicht auf das Ewige in unvergleichlich dichter Weise. Der Vers ist ein beliebtes Sendungslied in reformierten Gottesdiensten. Das ist sinnig. Jeder Gottesdienst enthält ein memento mori und ist gleichsam eine Abdankung vor der Zeit im Wissen darum, dass der Herr, der nimmt, auch gibt. Gelobt sei sein Name. »Der Du allen der Ewige heisst / und Anfang, Ziel und Mitte weisst / im Fluge unsrer Zeiten: / Bleib du uns gnädig zugewandt / und führe uns an deiner Hand, / damit wir sicher schreiten«. 